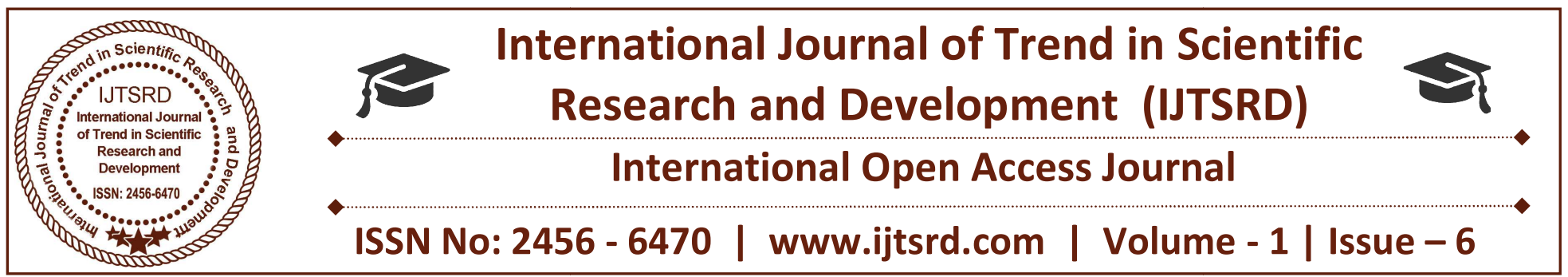

\title{
Effect of Electrical and Non-electrical Parameters on the Performance Measures of Electro-Discharge Machining: A Review
}

\author{
Anbesh Jamwal \\ PG Student, Industrial and \\ Production Engineering, Amity \\ University Noida, U.P.
}

\author{
Dr. Umesh Kumar Vates \\ Assistant Professor, Mechanical \\ Engineering Department, Amity \\ University, Noida, U.P.
}

\author{
Ankur Aggarwal \\ PG Student, Industrial and \\ Production Engineering, Amity \\ University Noida, U.P.
}

\begin{abstract}
The electrical and non-electrical parameters of EDM influence the performance of EDM. EDM is one of the widely used non-traditional machining process used for machine the hard materials which are difficult to machine by the conventional machining processes. In the past few decades EDM gains popularity because of its wide range of applications in the die-making, aerospace industry and other manufacturing sectors. It is also an alternative method of batch production when the conventional machining processes fail to machine a material. The development in the new hybrid techniques and new tool materials makes some new research scopes in the EDM. Lot of research has been done in EDM optimization, monitoring and its application area but still there are many research gaps which need further study. The aim of this paper to identify the effect of electrical and non-electrical parameters on the performance measures of EDM.
\end{abstract}

Keywords: Electro-discharge machining, EDM parameters, EDM characteristics

\section{INTRODUCTION}

In the present manufacturing scenario growth of any manufacturing industry depends upon the quality of its product and market reputation. However, the market reputation comes with the providing the quality of product to the consumer within a time. In the present time, the major problem is to machine the hard material like tungsten and achieve the high surface finish rates. This is a difficult task when it comes to conventional machining process but can be done by un-conventional machining processes like electro-discharge machining. EDM is the widely used non-conventional machining process (Goyal et al., 2016, Abbas et al., 2007, Vates and Singh, 2013). The electro-discharge machining has widely used in the production of dies and molds (Singh et al., 2004, Uhlmann et al., 2005). Basically, EDM is used to machine those materials which are difficult to machine by the conventional machining process. Finishing parts of aerospace and automobile industries are machined by the EDM process (Vates et al., 2016, Keskin et al., 2006, Chen and Mahdivian 2000). There is no direct contact between the tool material and work-piece (Lee and $\mathrm{Li}, 2001$, Sharma et al., 2016). The material is removed by the thermal erosion in the EDM process (Lin and Lin, 2002, Vates et al., 2016). Previously studied on EDM reported that the material removal rates are less in the EDM than the other conventional machining processes (Lauwers et al., 2007). The major advantage of using EDM rather than conventional machining processes is very high surface finish rates (Liao et al., 1997). The advantage of using EDM there are no mechanical vibrations and mechanical stresses occur during machining because of no direct contact between the work-piece and tool material (Ho et al., 2004). Another advantage of using EDM over other machining processes that it can machine any profile or geometry (Kansal et al., 2005). It can easily machine the complicated geometry which can be difficult to machine by some other machining processes (Tarng et al., 1995). But the limitation is 
only the tool material and work-piece must be electrically conducted (Goyal et al. 2016, Vates et al., 2016, Hocheng et al., 1997, Kruth et al.,1995) . This is one of the major requirements of the EDM (Amorim and Weingaertner, 2004). Generally used tool materials in the EDM are tungsten and copper (Mohri et al., 1995, Lee and Li, 2001). The EDM technique is developed in 1940 by two Russian scientists B.R Lazarenko and N.I Lazarenko (Ho and Newman, 2003). Later in 1967, the scientists of Soviet Union developed first EDM in which they used wire as the electrode ( Pandey and Singh, 2010). EDM utilizes the electrical energy to generate the electrical spark and the material removal is done by the thermal energy that is generated by the electrical spark (Skandesh et al., 2016). The tool material and work-piece are maintained by a small gap known as spark gap which is $0.005 \mathrm{~mm}-0.05 \mathrm{~mm}$ (Singh et al., 2004). There is the continuously electrical charges occurred between the tool and work-piece in the presence of the dielectric fluid (Jahan et al., 2009). The dielectric fluid may be the EDM oil and kerosene oil. The main purpose of the dielectric fluid is to provide the dielectric medium and flushing out the machining debris from the work table. The major disadvantage of the EDM is the overcutting and the formation of the recast layer. This is the research gap till now (Konig et al., 1998, Singh and Sharma, 2017). Current trends in the

EDM is carried by researchers on the machining techniques like Dry EDM, EDM with additives, EDM in water and the different modeling techniques for the better results (Imran et al., 2017, Indurkhya and Rajurkar, 1992, Kiran and Joshi, 2007, Spedding and Wang, 1997, Datta and Mahapatra, 2010). These days micro-EDM gains more popularity because it can achieve the surface finish up to the micro level (Pham et al., 2004, Hourmand et al., 2017). The power consumption is very less in the case of micro-EDM (Liu et al., 2010). These days EDM is using in the industries where the better surface finish is the major requirements (Samuelson and Björk, 2013).

\section{EDM PRINCIPLE AND CLASSIFICATION}

The material is removed in the EDM process through the repeated occurrence of sparks which are generated between the tool and work-piece at the small gap within the range of 10-125 $\mu \mathrm{m}$ (Singh et al., 2004, Goyal et al. 2014), The potential difference is applied between the tool material and the work-piece in the EDM process(Wu et al., 2005). The only limitation in the EDM machining process is that both the workpiece and tool material should be conductive in nature (Kruth et al., 1995). These days development of new conductive ceramic matrix materials made new scopes in the research area of EDM process optimization (Zhixin et al.,1995, Rona et al., 2017). When the electric supply given then the electric field is generated at the smallest gap between the work-piece and tool material ( $\mathrm{Su}$ et al. 2004). Microscopic contaminants in the dielectric fluids are attracted by the electric field and concentrated at the strongest point (Kunieda et al., 2015). These contaminate build up high conductivity bridge between the tool material and work-piece material (Puertas and Luis, 2003). As the voltage increases the material and high conductivity bridge heats up some contaminates ionized to form the spark channel between the tool material and work-piece (Prabhu and Vinayagam, 2011). With the increase in both the temperature and pressure at the strongest point of the field generated the spark (Kung et al., 2009). As a result, small amount of work-piece is melted and vaporizes from both the electrode and work-piece (Keksin et al., 2006). The generated spark removes the material from the work-piece and the machining debris is flushed out by the flushing actions of dielectric fluid (Jeswani, 1981). Both the tool material and work-piece is kept immersed in the dielectric fluid (Kumar et al., 2009). Generally, the EDM oil and kerosene oil used as the dielectric fluid. It is found in studies that tap water cannot be used as the dielectric fluid because of it breakdowns and ionize early due to the presence of salts (Ho et al., 2004). Dielectric fluid in EDM provides an oxygen-free machining environment hence gives better machining results (Kim and $\mathrm{Chu}$, 2007). Kerosene is highly used dielectric fluid. It prevents the De-Odoring and gas bubbles when mixed up with the other additives (Ming and He, 1995). It was found in the study that silicon fluids and a mixture of Silicon fluids with the petroleum oils give the excellent machining results than the others (Pecas and Henriques, 2003).

\section{Classification of EDM}

Basically, the EDM can be classified into Die-sinking EDM and Wire-EDM (Vates et al.,2016). However, both they have the same working principles but having different research areas and application areas (Singh et al., 2004). 


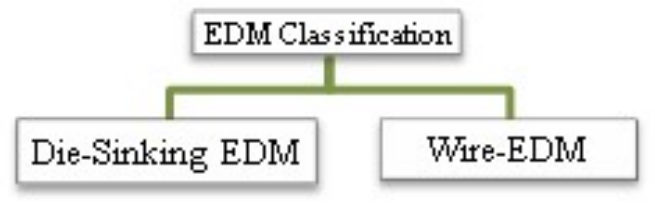

Die sinking EDM is also known as volume EDM or the cavity type EDM (Mohan et al., 2004). In which both the tool material and the work-piece are separated by a small gap and kept immersed in the dielectric fluid which helps the spark to concentrate at a particular point. Both the work-piece and tool material are connected to the power supply in the Diesinking EDM (Goyal et al., 2016). A large number of spark generated at the particular locations generally thousands spark per second with the actual duty cycles which are controlled by the input parameters. The "pulse-on-time" and "Pulse-off-time" are known as the controlling cycles (Muthuramalingam and Mohan, 2013). The pulse-on-time determines the length or the duration of spark during the machining. It is found in the studies that the higher values of pulse-on-time decrease the surface quality of the material (Krishna et al., 2008, Rao et al., 2010). Pulse-off-time is generally the period time when a spark is replaced by another spark. High values of pulse-off -time allows the dielectric fluid to flushing out and cleans the machining debris and avoiding the short circuits during the machining process.

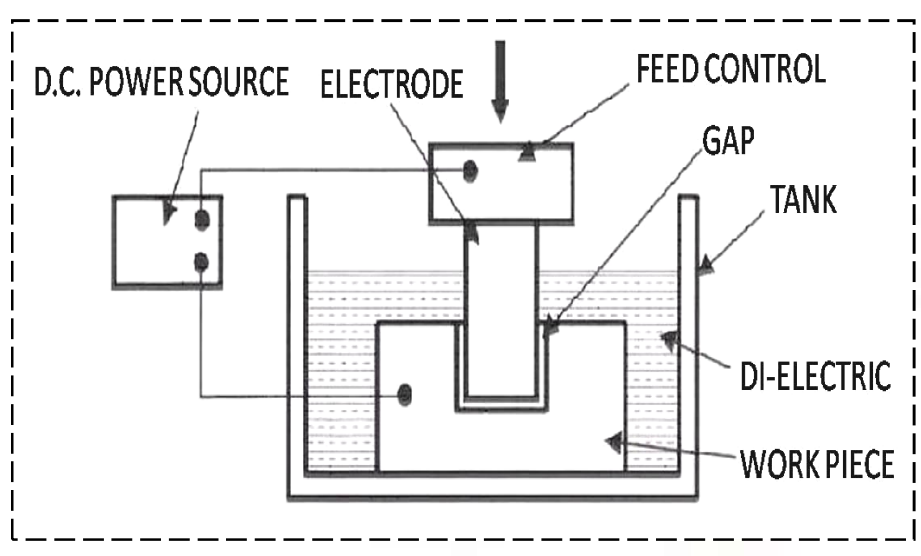

Figure: Die-Sinking EDM

A lot of research has been done on WEDM process development and its application areas (Vates et al. 2014, Chiang and Chang, 2006). The working principle of WEDM is same as the working principle of Die-sinking EDM (Aspinwall et al., 2008). WEDM is also known as Wire-cutting EDM or Wire-cut EDM. It is the special form of Electro discharge machining which uses a continuously moving wire electrode (Yuan et al. 2008). In the WEDM process, a thin wire is fed up through the work-piece which is submerged in the dielectric tank (Kozak et al. 2004). Ionized water is generally used as the dielectric fluid in the WEDM (Chaw et al., 2004). WEDM has a wide range of application in the manufacturing of dies and 3D shapes which are difficult to manufacture by other machining operations (Liao and $\mathrm{Yu}, 2004$ ). The main operation of the dielectric fluid is to flush out the machining debris from the cutting zone. Flushing of the dielectric fluid is the main factor which affects the feed rate or WEDM process.

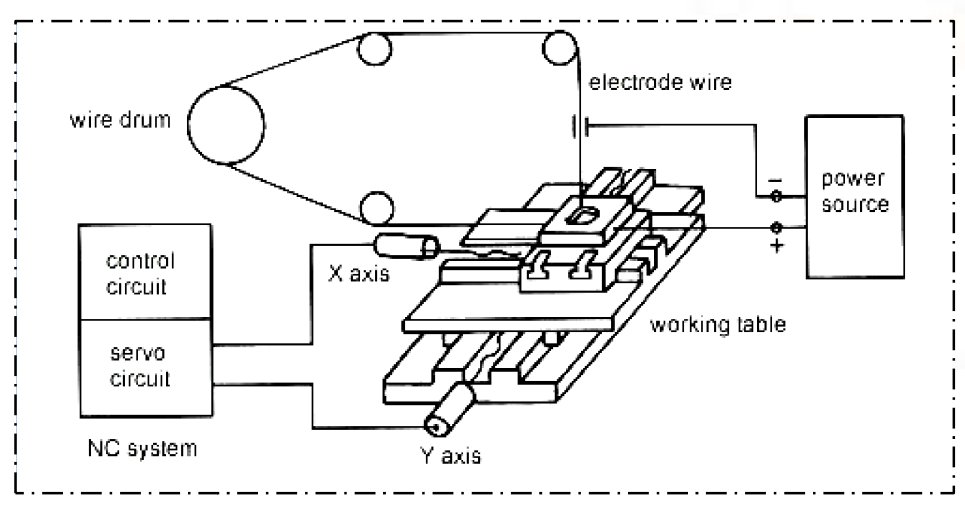

Figure: Wire-EDM

\section{DIELECTRIC FLUID AND ITS FLUSHING METHODS:}

Dielectric fluid acts as an insulating medium. The main aim of the dielectric fluid is to maintain the constant resistance across the gap between the tool
The dielectric fluid acts as a coolant or flushing medium in an EDM process. In the EDM process (Yan et al. 2005). material and work-piece (Singh and Bhardwaj, 2011). It was found in the studies that kerosene oil provides the excellent machining conditions when it mixed up 
with some other additives (Prihandana et al., 2009). The dielectric fluid is flushed out through the spark gap to remove the machining debris from the surface of work-piece. Flushing of machining debris from the gap is very important to avoid the short circuits (Luo, 1997). The cutting is irregular and machining conditions would be poor if the flushing process is applied incorrectly and also leads to decrease in the tool life and increased in production time (Jain, 2009) Flushing operation plays an important role in stable machining and achieving higher surface finish rates. There are four main dielectric flushing methods:

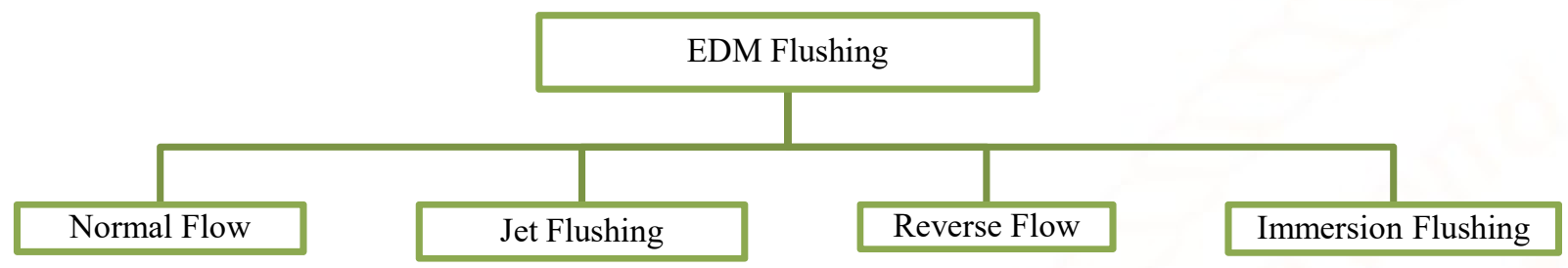

Figure: EDM Flushing Methods

Normal flushing method is generally used flushing method in the EDM processes. The dielectric fluid is introduced under a certain amount of pressure and forced to flow between the gap of tool material and work-piece (Masuzawa and Heuvelman, 1983). Sometimes it produces a tapered opening in the workpiece so sometimes it is undesirable. In the reverse flow flushing method, there is not taper opening in the work-piece a vacuum is used instead of pressure. Desired EDM machining conditions can be achieved by the jet flushing method. Sometimes it takes longer machining times than the Normal flow and Reverse flow flushing methods. Pumping and sucking action is used to remove the debris from the machining surface. Immersion flushing is valuable for the deep cavities and blind holes (Schumacher, 1990).

\section{LITREATURE REVIEW:}

EDM is one of the most popular and widely used among all non-traditional machining processes. A lot of research has been done on the EDM modeling, optimization of its process parameters and its applications. There are still many research gaps in the EDM applications and optimization of process parameters on ceramic materials.

(Asal et al., 2013) conducted an experiment to optimize the process parameters of EDM by the use of ANOVA. The pulse on time, current and spark gap were the main input parameters. The brass and copper took as electrode material with the DEF-92 as the dielectric fluid. The DOE is constructed through the

Minitab software he concluded that surface roughness increases with increase in the discharge current.
(Goyal et al., 2016) investigated the effect of input parameters such as Discharge current, voltage and pulse-on-time to optimize the responses such Tool wear rate, Material removal rate and surface quality with the copper as the tool material. It was concluded in the research that MRR and TWR increase with the increase in the values of discharge current and voltage and surface quality start decreasing with the increase in the values of pulse-on-time and discharge current. The optimal values of surface quality are found at a lower value of pulse-on-time and discharge current.

(Chandramouli et al.,2014) Conducted an experiment to investigating EDM process parameters by the use of Taguchi method. The effect of various input parameters on the output parameters is investigated by the Taguchi method. Discharge current, pulse-on-time and pulse-of-time were taken as input parameters to optimize the surface roughness, tool wear rate and material removal rate. It was concluded that in the research that material removal rate increases with the increase in the pulse on time and discharge current but it affects the surface quality of the material.

(Raghuraman et al., 2013) performed an experiment on the Mild Steel IS-2026 to optimize the output parameters MRR, TWR and surface roughness with the input parameters pulse-on-time, pulse-off-time and discharge current with the copper as tool material. It was found in the result that lower tool wear rate found at lower values of current and pulse on time and surface quality starts decreasing with increase in the discharge current and pulse-on-time. It was also found that the GRA is the best optimizing technique to optimize the process parameters. 
(Skandesh et al., 2016) investigated the effect of EDM on the magnesium nano-composite and concluded that these composite are lightly weighted and have the wide range of applications in the aerospace industry. Peak current, pulse-on-time, pulse-off-time and current density are taken as input parameters. It was found that the MRR increases with the increase in the pulse on time and surface finish majorly affect by the current.

(Modi et al., 2015) investigated the effect of both the electrical and non-electrical parameters on the EDM machining process and concluded that electrical parameters majorly influenced the output of EDM process than the non-electrical parameters. However, the powder additives increase the material removal rates. It was also concluded that Response surface methodology and Taguchi design are best techniques to optimize the process parameters.

(Krishna et al., 2008) investigated the effect of input parameters on the EDM using the ANN and genetic algorithm for the optimization of surface roughness. It was found in that surface finish decreases with the increase in current.

(Pradhan et al., 2014) stated that EDM is one of widely used non-traditional machining process having the wide range of applications in the aerospace industry. It was found in the experiment that the output parameters are majorly affected by the pulse on time, gap voltage, pulse off time and discharge current. High material removal rates can be achieved at the higher values of voltage and discharge current.

(Sharma et al., 2010) investigated the effects of EDM on the output parameters such as MRR, TWR and Surface quality using EDM with reverse polarity. The powder additives used during the machining process and it was found that powder additives increase the MRR but surface quality decreases.

(Singh et al., 2012) concluded that EDM can be used in the batch production of the hard materials which are difficult to machine by the conventional machining processes. However, the material removal rates are slower in the EDM but high surface rates can be achieved with the EDM. It was found in the study the MRR with the brass electrodes is increasing with increase in the Pulse on time and it was also found that on same parameters it starts decreasing when the copper electrode is used.
(Rao et al., 2010) investigated the effect of input parameters by the mathematical model on AISI 304 stainless steel material on output parameters such as TWR, MRR, Ra and HRB using fuzzy logic modeling. Regression analysis of experimental and predicted output was performed to investigate the model. It was concluded in the study that pulse on time affects the surface finish and MRR.

(Hindus et al., 2013) investigated the effect of EDM on the Stainless steel 316 L work-piece and concluded that Material removal rate linearly increased with increase in the discharge current. Tool wear rate is highly influenced by the current and then by pulse-ontime.

(Singh et al., 2011) studies the effect of EDM performance on the basis of output parameters like MRR, TWR, Relative Wear Ratio and Surface quality. The important EDM machining input parameters of the process are discharge current, pulse off time, arc gap pulse on time, duty cycle and arc gap. It was found that in the study that the mathematical modeling in the EDM still needs further studies and the development of new materials like composites have made new research scopes in the EDM optimization and its application. It was concluded in the study that discharge current is highly influenced parameter among all the parameters which affects the surface quality and Material removal rate.

(Banker et al., 2014) investigated the effect of EDM machining on the AISI 304 Steel by using Taguchi Method. L9 orthogonal array is used as the DOE for the experimentation. Copper is taken as the tool material for the experiment. Optimization process is done through the Minitab and Taguchi method. Pulseon-time, pulse-off-time and depth of cut were taken as input parameters to control the Material removal rate as the output parameter. It was found in the study that the copper has the higher material rates on steel materials with respect to aluminium, gunmetal and brass.

(Ghewade et al., 2011) studied the effect of EDM on the various parameters like gap voltage, pulse on time, Peak current and duty cycle on the Inconel-718 workpiece. Taguchi method is used to analyze the effect of input parameters on the output parameters. It was concluded that peak current and gap voltage are the main parameters which affects the MRR and Electrode wear rate is mainly influenced by the pulseon-time and duty cycle. 


\section{EFFECT OF ELECTRICAL AND NON- ELECTRICAL PARAMETERS}

Both Electrical and non-electrical parameters of EDM influence the performance of EDM. Electrical parameters majorly affect the performance of EDM than the non-electrical parameters.

\section{Effect of electrical parameters}

It is difficult to explain the effect of all electrical parameters on the performance due to the stochastic thermal nature of the electro-discharge machining. This section of the paper describes the research in the area of monitoring, control, and optimization of various electrical parameters which affect the performance of the EDM.

\section{Effect of peak current}

To investigate the effect of peak current in EDM on MRR and surface roughness pulse on time varied and other parameters like pulse off time, voltage and wire feed rate kept constant. The material removal rate is slow at low values of current and it is nearly constant as the values of current are low (Chen et al., 2013,Patel et al.,2011, Kumar et al., 2008). The material removal rate of material starts increasing the value of current increasing (Mandal and Saha, 2007, Rahman et al., 2011).

\section{Effect of pulse-on-time}

To observe the effect of pulse-on-time on the EDM performance peak current is varied while the other parameters like pulse-off-time, voltage and wire feed rate kept constant. It is observed that the MRR is increasing with the pulse-on-time at all the values of current and surface quality of material starts decreasing when there is an increase in the value of pulse-on-time (Khan et al.,2011, Habib, 2009, Pradhan and Biswas, 2008). Optimum values of surface roughness can be found at the lower value of pulse-on-time and current (Jiang et al.,2012).

\section{Effect of pulse-off-time}

It is found that MRR starts decreasing when there is an increase in the values of pulse-off-time. Long pulse-off-time makes a cooling effect on both the electrode and the work-piece material hence results in decreasing the cutting speed and EDM performance degradation (Lin et al., 2012, Goyal et al., 2016, Weng and Her, 2002). Surface roughness improves with the higher values of pulse-off-time. It was also found in some studies that first the surface roughness decreasing with the pulse-off-time then starts increasing when there is an increase in the values of pulse-off-time (Bhattacharyya et al., 2007, Marafona and Wykes, 2000, Lee et al., 1990).

\section{Effect of servo voltage}

The effect of servo voltage on the performance of EDM is observed by varying the pulse duration and kept constant all other parameters. MRR starts increasing with increase in the servo voltage initially. But then starts decreasing with increase in the servovoltage (Sanchez et al., 2001, Jain et al., 2007, Reddy and Rao, 2005). On other hand surface quality of material also starts decreasing with increase in the voltage (Sarkar et al., 2006).

\section{Effect of non-electrical parameters}

Beside the electrical parameters, non-electrical parameters also influence the performance of EDM. The flushing of dielectric fluid, rotational movement of work-piece and electrode plays an important role in achieving the desired performance measure in the EDM.

\section{Effect of dielectric flushing}

Dielectric flushing affects the performance measures of EDM. During the roughing operations, flushing of dielectric fluid affects the tool wear rate and electrode wear rate while during the finishing operations it affects the surface roughness (Wong et al., 1995, Kagaya et al., 1986). In addition, different properties of dielectric fluids also play a vital role in the performance of EDM. It was found in the studies the kerosene oil with additives provides the excellent EDM performance and high MRR and low electrode wear rate can be achieved without formation of any metal carbide on the surface of work-piece (Benedict, 1987). The flushing methods can classify into: Normal flow flushing (Wong et al., 1995), Jet flow flushing (Masuzawa et al., 1992), Immersion flow flushing (Makenzi and Ikua, 2014, Backman, 1990) and reverse flow flushing (Wong et al., 1995). Some researchers applied the magnetic field to move the debris from the gap and some applied the forced vibrations to move the machining debris from the gap between tool material and work-piece (Bruijn et al., 1978). 


\section{Effect of rotational movement of tool material}

Besides the dielectric flushing effect on the performance of EDM, the rotational movement of tool material also affects the performance measures of EDM. Better surface quality and material removal rate be achieved by the applying the rotational movement of tool material over the work-piece by improving the circulation of dielectric fluid in the spark gap (Enache et al., 1990, Murti and Philip, 1986).

\section{Effect of rotational movement of work-piece material}

Rotational movement of work-piece material in EDM improves the performance measures of EDM in terms of surface quality and material removal rate (Kunieda and Masuzawa, 1998, Mohri et al., 1989). The rotation of work-piece improves the dielectric flushing over the work-piece which results in the better surface quality and low electrode wear rate and High material removal rates (Soni and Chakraverti, 1994, Enache, 1993). Still, these non-electrical parameters need further study.

\section{CONCLUSION}

It was found that both the electrical and non-electrical parameters affect the performance measures of EDM. Material removal rate in EDM is increased with the increase in the discharge current. Higher the intensity of the spark results in the higher material removal rate but it affects the surface quality. The surface roughness increases with the higher values of the discharge current. It is also found in the study that higher the pulse-on-time also affects the material removal rate. MRR starts decreasing when the values of pulse-on-time start increasing. Long pulse-off-time increase the surface quality and on other hand, nonelectrical parameters such as dielectric flushing play major role in achieving the good surface quality. Rotational movement of work-piece and tool material improves the flushing of dielectric fluid which helps in flushing out of machining debris and improves the material removal rate and surface quality. The introduction of EDM in the manufacturing sector has changed the manufacturing scenario for the production of highly precise parts, 3D shapes, and aerospace industry. The new advancement in the conductive materials has made some new research scopes and application areas in EDM. However, there are many research gaps in EDM which stills needs further studies.

\section{REFERENCES}

[1] Abbas, N. M., Solomon, D. G., \& Bahari, M. F. (2007). A review on current research trends in electrical discharge machining (EDM). International Journal of machine tools and Manufacture, 47(7), 1214-1228.

[2] Amorim, F. L., \& Weingaertner, W. L. (2004). Die-sinking electrical discharge machining of a highstrength copper-based alloy for injection molds. Journal of the Brazilian Society of Mechanical Sciences and Engineering, 26(2), 137-144.

[3] Aspinwall, D. K., Soo, S. L., Berrisford, A. E., \& Walder, G. (2008). Workpiece surface roughness and integrity after WEDM of Ti-6Al-4V and Inconel 718 using minimum damage generator technology. CIRP Annals-Manufacturing Technology, 57(1), 187190.

[4] Backman, S. (1990). U.S. Patent No. 4,927,547. Washington, DC: U.S. Patent and Trademark Office.

[5] Bhattacharyya, B., Gangopadhyay, S., \& Sarkar, B. R. (2007). Modelling and analysis of EDM ED job surface integrity. Journal of Materials Processing Technology, 189(1), 169-177.

[6] Chen, D. C., Jhang, J. J., \& Guo, M. W. (2013). Application of Taguchi design method to optimize the electrical discharge machining. Journal of Achievements in Materials and Manufacturing Engineering, 57(2), 76-82.

[7] Chen, Y., \& Mahdivian, S. M. (2000). Analysis of electro-discharge machining process and its comparison with experiments. Journal of Materials Processing Technology, 104(1), 150-157.

[8] Chiang, K. T., \& Chang, F. P. (2006). Optimization of the WEDM process of particlereinforced material with multiple performance characteristics using grey relational analysis. Journal of Materials Processing Technology, 180(1), 96-101.

[9] Chow, H. M., Yang, L. D., Lin, C. T., \& Chen, Y. F. (2008). The use of $\mathrm{SiC}$ powder in water as dielectric for micro-slit EDM machining. Journal of materials processing technology, 195(1), 160-170.

[10] Datta, S., \& Mahapatra, S. (2010). Modeling, simulation and parametric optimization of wire EDM process using response surface methodology coupled 
with grey-Taguchi technique. International Journal of Engineering, Science and Technology, 2(5), 162-183.

[11] Enache, S., \& Opran, C. (1993). Dynamic stability of the technological machining system in EDM. CIRP Annals-Manufacturing Technology, 42(1), 209-214.

[12] G.F. Benedict, Electrical discharge machining (EDM), in: Nontraditional Manufacturing Processes, Marcel Dekker, Inc, New York \& Basel, 1987, pp. 211-213.

[13] Goyal, S., \& Singh, R. K. (2014). Parametric Study of Powder Mixed EDM and Optimization of MRR \& Surface Roughness. Carbon, 100, 0-43.

[14] Goyal, S., Jamwal, A., \& Pandey, R. (2016). Optimization of Process Parameters in ElectroDischarge Machining using Taguchi Method. Carbon, 100, 0-14.

[15] H.E. De Bruijn, T.H. Delft, A.J. Pekelaring, Effect of a magnetic 1300 K.H. Ho, S.T. Newman / International Journal of Machine Tools \& Manufacture 43 (2003) 1287-1300 field on the gap cleaning in EDM, Ann. CIRP 27 (1) (1978) 93-95.

[16] Habib, S. S. (2009). Study of the parameters in electrical discharge machining through response surface methodology approach. Applied Mathematical Modelling, 33(12), 4397-4407.

[17] Ho, K. H., \& Newman, S. T. (2003). State of the art electrical discharge machining (EDM). International Journal of Machine Tools and Manufacture, 43(13), 1287-1300.

[18] Ho, K. H., Newman, S. T., Rahimifard, S., \& Allen, R. D. (2004). State of the art in wire electrical discharge machining (WEDM). International Journal of Machine Tools and Manufacture, 44(12), 12471259.

[19] Hocheng, H., Lei, W. T., \& Hsu, H. S. (1997). Preliminary study of material removal in electricaldischarge machining of SiC/Al. Journal of Materials Processing Technology, 63(1-3), 813-818.

[20] Hourmand, M., Sarhan, A. A., \& Sayuti, M. (2017). Micro-electrode fabrication processes for micro-EDM drilling and milling: a state-of-the-art review. The International Journal of Advanced Manufacturing Technology, 91(1-4), 1023-1056.
[21] Imran, M., Shah, M., Mehmood, S., \& Arshad, R. (2017). EDM of Aluminum Alloy 6061 Using Graphite Electrode Using Paraffin Oil and Distilled Water as Dielectric Medium. Advances in Science and Technology. Research Journal, 11(3), 72-79.

[22] Indurkhya, G., \& Rajurkar, K. P. (1992). Artificial Neural Network approach in modelling of EDM process. In Proceedings of the 1992 Artificial Neural Networks in Engineering, ANNIE'92. ASME.

[23] Jahan, M. P., Wong, Y. S., \& Rahman, M. (2009). A study on the fine-finish die-sinking microEDM of tungsten carbide using different electrode materials. Journal of materials processing technology, 209(8), 3956-3967.

[24] Jain, N. K., Jain, V. K., \& Deb, K. (2007). Optimization of process parameters of mechanical type advanced machining processes using genetic algorithms. International Journal of Machine Tools and Manufacture, 47(6), 900-919.

[25] Jain, V. K. (2009). Advanced machining processes. Allied publishers.

[26] Jeswani, M. L. (1981). Effect of the addition of graphite powder to kerosene used as the dielectric fluid in electrical discharge machining. Wear, 70(2), 133-139.

[27] Jiang, Y., Zhao, W., \& Xi, X. (2012). A study on pulse control for small-hole electrical discharge machining. Journal of Materials Processing Technology, 212(7), 1463-1471.

[28] Kagaya, K., Ōishi, Y., \& Yada, K. (1986). Micro-electrodischarge machining using water as a working fluid-I: micro-hole drilling. Precision Engineering, 8(3), 157-162.

[29] Kansal, H. K., Singh, S., \& Kumar, P. (2005). Parametric optimization of powder mixed electrical discharge machining by response surface methodology. Journal of materials processing technology, 169(3), 427-436.

[30] Keskin, Y., Halkacı, H. S., \& Kizil, M. (2006). An experimental study for determination of the effects of machining parameters on surface roughness in electrical discharge machining (EDM). The International Journal of Advanced Manufacturing Technology, 28(11), 1118-1121. 
[31] Keskin, Y., Halkacı, H. S., \& Kizil, M. (2006). An experimental study for determination of the effects of machining parameters on surface roughness in electrical discharge machining (EDM). The International Journal of Advanced Manufacturing Technology, 28(11), 1118-1121.

[32] Khan, M. A. R., Rahman, M. M., Kadirgama, K., Maleque, M. A., \& Bakar, R. A. (2011). Artificial intelligence model to predict surface roughness of Ti15-3 alloy in EDM process. World Academy of Science, Engineering and Technology, 74, 198-202.

[33] Kim, B. H., \& Chu, C. N. (2007). Micro electrical discharge milling using deionized water as a dielectric fluid. Journal of Micromechanics and Microengineering, 17(5), 867.

[34] Kiran, M. K., \& Joshi, S. S. (2007). Modeling of surface roughness and the role of debris in microEDM. Journal of manufacturing science and engineering, 129(2), 265-273.

[35] König, W., Dauw, D. F., Levy, G., \& Panten, U. (1988). EDM-future steps towards the machining of ceramics. CIRP Annals-Manufacturing Technology, 37(2), 623-631.

[36] Kozak, J., Rajurkar, K. P., \& Chandarana, N. (2004). Machining of low electrical conductive materials by wire electrical discharge machining (WEDM). Journal of materials processing technology, 149(1), 266-271.

[37] Kruth, J. P., Stevens, L., Froyen, L., \& Lauwers, B. (1995). Study of the white layer of a surface machined by die-sinking electro-discharge machining. CIRP Annals-Manufacturing Technology, 44(1), 169-172.

[38] Kruth, J. P., Stevens, L., Froyen, L., \& Lauwers, B. (1995). Study of the white layer of a surface machined by die-sinking electro-discharge machining. CIRP Annals-Manufacturing Technology, 44(1), 169-172.

[39] Kumar, J., Khamba, J. S., \& Mohapatra, S. K. (2008). An investigation into the machining characteristics of titanium using ultrasonic machining. International Journal of Machining and Machinability of Materials, 3(1-2), 143-161.

[40] Kumar, S., Singh, R., Singh, T. P., \& Sethi, B. L. (2009). Surface modification by electrical discharge machining: a review. Journal of Materials Processing Technology, 209(8), 3675-3687.

[41] Kung, K. Y., Horng, J. T., \& Chiang, K. T. (2009). Material removal rate and electrode wear ratio study on the powder mixed electrical discharge machining of cobalt-bonded tungsten carbide. The International Journal of Advanced Manufacturing Technology, 40(1-2), 95-104.

[42] Kunieda, M. (2015). Electrical Discharge Machining Processes. In Handbook of Manufacturing Engineering and Technology (pp. 1551-1580). Springer London.

[43] Kunieda, M., \& Masuzawa, T. (1988). A fundamental study on a horizontal EDM. CIRP Annals-Manufacturing Technology, 37(1), 187-190.

[44] Lauwers, B., Kruth, J. P., \& Brans, K. (2007). Development of technology and strategies for the machining of ceramic components by sinking and milling EDM. CIRP Annals-Manufacturing Technology, 56(1), 225-228.

[45] Lee, L. C., Lim, L. C., Wong, Y. S., \& Lu, H. H. (1990). Towards a better understanding of the surface features of electro-discharge machined tool steels. Journal of Materials Processing Technology, 24, 513-523.

[46] Lee, S. H., \& Li, X. P. (2001). Study of the effect of machining parameters on the machining characteristics in electrical discharge machining of tungsten carbide. Journal of materials processing Technology, 115(3), 344-358.

[47] Liao, Y. S., \& Yu, Y. P. (2004). Study of specific discharge energy in WEDM and its application. International Journal of Machine Tools and Manufacture, 44(12), 1373-1380.

[48] Liao, Y. S., Huang, J. T., \& Su, H. C. (1997). A study on the machining-parameters optimization of wire electrical discharge machining. Journal of materials processing technology, 71(3), 487-493.

[49] Lin, C. L., Lin, J. L., \& Ko, T. C. (2002). Optimisation of the EDM process based on the orthogonal array with fuzzy logic and grey relational analysis method. The International Journal of Advanced Manufacturing Technology, 19(4), 271277. 
[50] Lin, J. L., \& Lin, C. L. (2002). The use of the orthogonal array with grey relational analysis to optimize the electrical discharge machining process with multiple performance characteristics. International Journal of Machine Tools and Manufacture, 42(2), 237-244.

[51] Liu, K., Lauwers, B., \& Reynaerts, D. (2010). Process capabilities of Micro-EDM and its applications. The International Journal of Advanced Manufacturing Technology, 47(1), 11-19.

[52] Luo, Y. F. (1997). The dependence of interspace discharge transitivity upon the gap debris in precision electrodischarge machining. Journal of materials processing technology, 68(2), 121-131.

[53] Mandal, D., Pal, S. K., \& Saha, P. (2007). Modeling of electrical discharge machining process using back propagation neural network and multiobjective optimization using non-dominating sorting genetic algorithm-II. Journal of Materials Processing Technology, 186(1), 154-162.

[54] Marafona, J., \& Wykes, C. (2000). A new method of optimising material removal rate using EDM with copper-tungsten electrodes. International Journal of Machine Tools and Manufacture, 40(2), 153-164.

[55] Masuzawa, T., \& Heuvelman, C. J. (1983). A self-flushing method with spark-erosion machining. CIRP Annals-Manufacturing Technology, 32(1), 109111.

[56] Masuzawa, T., Cui, X., \& Taniguchi, N. (1992). Improved jet flushing for EDM. CIRP Annals-Manufacturing Technology, 41(1), 239-242.

[57] Masuzawa, T., Tsukamoto, J., \& Fujino, M. (1989). Drilling of deep microholes by EDM. CIRP Annals-Manufacturing Technology, 38(1), 195-198.

[58] Ming, Q. Y., \& He, L. Y. (1995). Powdersuspension dielectric fluid for EDM. Journal of materials processing technology, 52(1), 44-54.

[59] Mohan, B., Rajadurai, A., \& Satyanarayana, K. G. (2004). Electric discharge machining of Al-SiC metal matrix composites using rotary tube electrode. Journal of materials processing technology, 153, 978985.

[60] Mohri, N., Suzuki, M., Furuya, M., Saito, N., \& Kobayashi, A. (1995). Electrode wear process in electrical discharge machinings. CIRP AnnalsManufacturing Technology, 44(1), 165-168.

[61] Murti, V. S. R., \& Philip, P. K. (1987). A comparative analysis of machining characteristics in ultrasonic assisted EDM by the response surface methodology. International Journal of Production Research, 25(2), 259-272.

[62] Muthuramalingam, T., \& Mohan, B. (2013). Influence of discharge current pulse on machinability in electrical discharge machining. Materials and Manufacturing Processes, 28(4), 375-380.

[63] Pandey, A., \& Singh, S. (2010). Current research trends in variants of Electrical Discharge Machining: A review. International Journal of Engineering Science and Technology, 2(6), 21722191.

[64] Patel, V. D., Patel, C. P., \& Patel, U. J. (2011). Analysis of different tool material on MRR and surface roughness of mild steel in EDM. International Journal of Engineering Research and Applications, 1(3), 394-397.

[65] Pecas, P., \& Henriques, E. (2003). Influence of silicon powder-mixed dielectric on conventional electrical discharge machining. International Journal of Machine Tools and Manufacture, 43(14), 14651471.

[66] Pham, D. T., Dimov, S. S., Bigot, S., Ivanov, A., \& Popov, K. (2004). Micro-EDM-recent developments and research issues. Journal of Materials Processing Technology, 149(1), 50-57.

[67] Prabhu, S., \& Vinayagam, B. K. (2011). AFM surface investigation of Inconel 825 with multi wall carbon nano tube in electrical discharge machining process using Taguchi analysis. Archives of civil and mechanical engineering, 11(1), 149-170.

[68] Pradhan, M. K., \& Biswas, C. K. (2008). Modelling of machining parameters for MRR in EDM using response surface methodology.

[69] Prihandana, G. S., Mahardika, M., Hamdi, M., Wong, Y. S., \& Mitsui, K. (2009). Effect of micropowder suspension and ultrasonic vibration of dielectric fluid in micro-EDM processes-Taguchi approach. International Journal of Machine Tools and Manufacture, 49(12), 1035-1041. 
[70] Puertas, I., \& Luis, C. J. (2003). A study on the machining parameters optimisation of electrical discharge machining. Journal of materials processing technology, 143, 521-526.

[71] Rahman, M. M., Khan, M. A. R., Kadirgama, K., Noor, M. M., \& Bakar, R. A. (2011). Experimental investigation into electrical discharge machining of stainless steel 304. Journal of Applied Sciences, 11, 549-554.

[72] Reddy, N. S. K., \& Rao, P. V. (2005). Selection of optimum tool geometry and cutting conditions using a surface roughness prediction model for end milling. The International Journal of Advanced Manufacturing Technology, 26(11-12), 1202-1210.

[73] Rona, N., Yenisey, M., Kucukturk, G., Gurun, H., Cogun, C., \& Esen, Z. (2017). Effect of electrical discharge machining on dental Y-TZP ceramic-resin bonding. Journal of prosthodontic research, 61(2), 158-167.

[74] S. Enache, C. Opran, G. Stoica, E. Strajescu, The study of EDM with forced vibration of tool electrode, Ann. CIRP 39 (1) (1990) 167-170.

[75] Samuelson, O., \& Björk, B. C. (2013). Adoption processes for EDM, EDI and BIM technologies in the construction industry. Journal of Civil Engineering and Management, 19(sup1), S172S187.

[76] Sanchez, J. A., Cabanes, I., de Lacalle, L. L., \& Lamikiz, A. (2001). Development of optimum electrodischarge machining technology for advanced ceramics. The International Journal of Advanced Manufacturing Technology, 18(12), 897-905.

[77] Sarkar, B.R.; Doloi, B.; Bhattacharyya, B. Parametric analysis on electrochemical discharge machining of silicon nitride ceramics. International Journal of Advanced Manufacturing Technology 2006, 28, 873-881.

[78] Schumacher, B. M. (1990). About the role of debris in the gap during electrical discharge machining. CIRP Annals-Manufacturing Technology, 39(1), 197-199.

[79] Sharma, S., Singh, G. K., Vates, U. K., \& Kumar, S. (2016). Experimental Investigation and Optimization of Surface Roughness of Die Steel in WEDM Process with Influence of Heat Treatment.
[80] Singh, J., \& Sharma, R. K. (2017). Experimental investigation of process parameters for conductive graphite abrasive mixed EDM of WC alloy. International Journal of Abrasive Technology, $8(1), 25-43$.

[81] Singh, P. N., Raghukandan, K., \& Pai, B. C. (2004). Optimization by grey relational analysis of EDM parameters on machining $\mathrm{Al}-10 \% \mathrm{SiC} \mathrm{P}$ composites. Journal of Materials Processing Technology, 155, 1658-1661.

[82] Singh, S., \& Bhardwaj, A. (2011). Review to EDM by using water and powder-mixed dielectric fluid. Journal of Minerals and Materials Characterization and Engineering, 10(02), 199.

[83] Singh, S., Maheshwari, S., \& Pandey, P. C. (2004). Some investigations into the electric discharge machining of hardened tool steel using different electrode materials. Journal of materials processing technology, 149(1), 272-277.

[84] Soni, J. S., \& Chakraverti, G. (1994). Machining characteristics of titanium with rotary electro-discharge machining. Wear, 171(1-2), 51-58.

[85] Spedding, T. A., \& Wang, Z. Q. (1997). Study on modeling of wire EDM process. Journal of Materials Processing Technology, 69(1-3), 18-28.

[86] Su, J. C., Kao, J. Y., \& Tarng, Y. S. (2004). Optimisation of the electrical discharge machining process using a GA-based neural network. The International Journal of Advanced Manufacturing Technology, 24(1-2), 81-90.

[87] Tarng, Y. S., Ma, S. C., \& Chung, L. K. (1995). Determination of optimal cutting parameters in wire electrical discharge machining. International Journal of Machine Tools and Manufacture, 35(12), 1693-1701.

[88] Uhlmann, E., Piltz, S., \& Doll, U. (2005). Machining of micro/miniature dies and moulds by electrical discharge machining - recent development. Journal of Materials Processing Technology, 167(2), 488-493.

[89] Vates, U. K., \& Singh, N. K. (2013). Optimization of Surface Roughness Process Parameters of Electrical Discharge Machining of EN31 by Response Surface Methodology. International Journal of Engineering, 6(6), 835-840. 
[90] Vates, U. K., Singh, N. K., \& Singh, R. V. (2014). Modelling of Process Parameters on D2 Steel using Wire Electrical Discharge Machining with combined approach of RSM and ANN. International Journal of Scientific \& Engineering Research, 5(1), 2026-2035.

[91] Vates, U. K., Singh, N. K., \& Singh, R. V. (2016). Modelling and optimisation of wire electrical discharge machining process on D2 steel using ANN and RMSE approach. International Journal of Computational Materials Science and Surface Engineering, 6(3-4), 161-185.

[92] Vates, U. K., Singh, N. K., \& Singh, R. V. (2016). Modelling and optimisation of wire electrical discharge machining process on D2 steel using ANN and RMSE approach. International Journal of Computational Materials Science and Surface Engineering, 6(3-4), 161-185.

[93] Weng, F. T., \& Her, M. G. (2002). Study of the batch production of micro parts using the EDM process. The international journal of advanced manufacturing technology, 19(4), 266-270.

[94] Wong, Y. S., Lim, L. C., \& Lee, L. C. (1995). Effects of flushing on electro-discharge machined surfaces. Journal of Materials Processing Technology, 48(1-4), 299-305.

[95] Wu, K. L., Yan, B. H., Huang, F. Y., \& Chen, S. C. (2005). Improvement of surface finish on SKD steel using electro-discharge machining with aluminum and surfactant added dielectric. International Journal of Machine Tools and Manufacture, 45(10), 1195-1201.

[96] Yan, B. H., Tsai, H. C., \& Huang, F. Y. (2005). The effect in EDM of a dielectric of a urea solution in water on modifying the surface of titanium. International Journal of Machine Tools and Manufacture, 45(2), 194-200.

[97] Yuan, J., Wang, K., Yu, T., \& Fang, M. (2008). Reliable multi-objective optimization of highspeed WEDM process based on Gaussian process regression. International Journal of Machine Tools and Manufacture, 48(1), 47-60.

[98] Zhixin, J., Jianhua, Z., \& Xing, A. (1995). Ultrasonic vibration pulse electro-discharge machining of holes in engineering ceramics. Journal of materials processing technology, 53(3-4), 811-816. 